Kopp first proceeded to sketch the methods employed for determining the molecular and atomic weights of the elements. When an element can be volatilised conveniently, so that we can obtain its vapour-density, its molecular weight is readily decided. Those elements which enter with a large number of volatile, or gaseous bodies, like carbon, present but little difficulty. Those, like zinc, which form but one class of volatile compounds, leave much to be desired, for a series of homologous bodies are no better than a single member of the series. In this case, however, the specific heat of the element comes to our aid, and we can usually take such a multiple of its equivalent as will give, when multiplied by the specific heat, a product not far from six. Naumann's law also enables us to make use of the specific heat of salts as well as that of the elements, the product of the specific heat by the sum of the atomic weights being nearly equal for similar compounds, and usually six times that of the number of atoms in a molecule. But this fails in some cases, probably, because we cannot take the specific heat at a sufficiently high temperature, as in the case of ice. In many cases where the above tests fail, isomorphism holds good. But totally unlike bodies, containing an unlike number of atoms in the molecule, have the same crystalline form. To avoid this dilemma, Prof. Kopp proposes to limit the term isomorphous to those compounds which possess the same crystal-forming power, as proved by their ability to crystallise together, or, if unequal in solubility, the ability of one crystal to grow in a solution of the other. Both of these cases were beautifully illustrated by alums. If a trace of a chromalum solution be added to a solution of potash-alum, each crystal that forms will contain both, as shown by the reddish tinge, and the colour deepens as the quantity of chromalum added is increased. On the other hand, when a crystal of one sort of alum is placed in a solution of the other kind, it continues to grow. Fine specimens of such crystals were exhibited by the speaker, who is remarkably skilful in this matter of growing and nursing crystals. Many other isomorphous salts were exhibited, such as the sulphates of magnesia and nickel; in some cases two different salts had been deposited alternately over the crystal of a third salt. Most interesting were rhombohedra of calxspar covered with nitrate of sodium, thus proving these two bodies isomorphous. The professor acknowledged that he had had much difficulty in obtaining these, and had utterly failed to make a crystal of arragonite grow in a solution of nitrate of potash. Prof. Kopp said, in conclusion, that unlike number of atoms could not replace each other in a molecule of two isomorphous bodies. Sulphate of cadmium will crystallise with eight equivalents of water to three of the anhydrous salt. Sulphate of didymium crystallises with eight equivalents of water. Both have the same crystalline form, but two atoms of didymium seem to replace the three of cadmium :-

$$
\begin{aligned}
& \mathrm{Di}_{2} \mathrm{~S}_{3} \mathrm{O}_{12}+8 \mathrm{H}_{2} \mathrm{O} ; \\
& \mathrm{Cd}_{3} \mathrm{~S}_{3} \mathrm{O}_{12}+8 \mathrm{H}_{2} \mathrm{O} .
\end{aligned}
$$

But these salts will not crystallise together, and crystals of the latter, from a mixed solution, contain no pinkish tinge of didymium.

\section{HER MAJESTY'S ASTRONOMER AT THE CAPE}

MR. DAVID GILL has been gazetted successor to Mr. E. J. Stone in the direction of the Royal Observatory, Cape of Good Hope. The discrimination exercised by the First Lord of the Admiralty in this appointment, we are confident will be appreciated and applauded by astronomers generally. Obtaining his first experience in practical astronomy in the Observatory at Aberdeen, and in a private observatory which be erected in the same place, Mr. Gill was so fortunate as to be associated with Lord Lindsay in the designs and details of the large observatory founded by this nobleman at Dun Echt in 1870, taking the position of chief of the staff. He thus became engaged in the organisation of the expedition to the Mauritius fitted out by Lord Lindsay for the observation of the transit of Venus, on which occasion advantage was taken of the circumstance of a heliometer forming part of the equipment to determine the sun's distance by measures of the planet Juno, being the first trial of the method, and attended with satisfactory results; the details of this work were published by Lord Lindsay as the joint work of himself and Mr. Gill. In connection with the same expedition, Mr. Gill arranged and personally conducted the whole of the chronometric and telegraphic longitude determinations connecting Berlin, Malta, Alexandria, Suez, Aden, Bombay, Seychelles, Reunion, Mauritius, and Rodriguez. It was while engaged upon these operations that he undertook, at the request of the Khedive, the measurement of the first base line of the geodetic survey of Egypt. In I $877 \mathrm{Mr}$. Gill laid before the Royal Astronomical Society a proposal to determine the sun's distance by heliometric observations of the planet Mars about the very favourable opposition of that year, Lord Lindsay lending his heliometer for the purpose. The proposal met with the support of the Astronomer-Royal and Council of this Society, and was further aided in its execution by a grant from the government funds in the hands of the Royal Society. The Island of Ascension was fixed upon as a favourable station for these observations, and Mr. Gill proceeded to Ascension in June, being occupied there about six months in the necessary preparations and carrying out of the scheme. The reductions are still proceeding, but in proof of the importance attached to this attempt to obtain a reliable value of the solar parallax and the interest felt by the leading astronomers of different nations in his work, it may be mentioned that on asking for aid in the accurate determination of the positions of the stars observed with Mars, his request was cordially acceded to at the following observatories :- Greenwich, Oxford, and Liverpool, Albany, U.S., Berlin, Cambridge, Mass., Cordoba (the national establishment of the Argentine Republic), Königsberg, Leipsic, Leyden, Melbourne, Paris, Pulkova (the Imperial Observatory of Russia), and Washington.

We will express the hope that Mr. Gill may carry to his new sphere a continuance of the great energy he has hitherto shown and repeat our conviction that his nomination by the First Lord to the important position of "Her Majesty's Astronomer at the Cape," will be hailed with great satisfaction in the astronomical world. It is understood that Mr. Gill leaves England early in May, arriving at the Cape in good time to confer with Mr. Stone upon the future work of the Observatory.

\section{OUR ASTRONOMICAL COLUMN}

The Naval ObServatory, Washingron.-The Report of Admiral Rodgers, superintendent of this great astronomical establishment, for the year 1878 has just been issued. The operations of the institution have been more than usually extended, involving expeditions for the observation of the transit of Mercury on May 8 , and the total solar eclipse of July 29 . The 26 -inch refractor has been in charge of Prof. Asaph Hall, with Prof. Holden as assistant, and has been constantly employed in the observation of satellites, double stars, and nebulæ, and occasionally of comets. Admiral Rodgers mentions that many foreign astronomers visiting the United States on the occasion of the eclipse, took the opportunity of inspecting this instrument, expressing very generally an opinion that the mounting was too light, and in this opinion the superintendent to a certain degree coincides, 